\title{
Novas citações de Chytridiomycota e Oomycota para o Parque Estadual das Fontes do Ipiranga (PEFI), SP, Brasil
}

\author{
Carmen Lidia Amorim Pires-Zottarelli ${ }^{1,2}$ e Maristela Rocha ${ }^{1}$
}

Recebido em 8/11/2005. Aceito em 17/08/2006

\begin{abstract}
RESUMO - (Novas citações de Chytridiomycota e Oomycota para o Parque Estadual das Fontes do Ipiranga (PEFI), SP, Brasil). Levantamento de fungos zoospóricos realizado em lagos artificiais do Parque Estadual das Fontes do Ipiranga (PEFI), situado na cidade de São Paulo, Estado de São Paulo, Brasil, resultou no isolamento de 41 táxons, sendo 36 identificados em nível específico. Vinte e três táxons pertencem ao Reino Fungi, filo Chytridiomycota, ordens Chytridiales, Monoblepharidales e Spizellomicetales e, 18 ao Reino Straminipila, filo Oomycota, ordens Saprolegniales e Peronosporales. Dentre os fungos isolados, 14 são mencionados pela primeira vez para o PEFI: Aphanomyces helicoides von Minden, Catenochytridium kevorkianii Sparrow, Catenochytridium sp., Chytriomyces appendiculatus Karling, C. aureus Karling, C. hyalinus Karling, C. spinosus Fay, Diplophlyctis asteroidea Dogma, D. complicata (Willoughby) Dogma, Karlingia dubia Karling, Nowakowskiella hemisphaerospora Shanor, Saprolegnia australis Elliott, Septochytrium variabile Berdan e Truittella sp., os quais são descritos, comentados e ilustrados. O gênero Truitella é mencionado pela primeira vez para o Brasil.
\end{abstract}

Palavras-chave: diversidade, Chytridiomycota, Oomycota, Mata Atlântica, Brasil

\begin{abstract}
New records of Chytridiomycota and Oomycota from the "Parque Estadual das Fontes do Ipiranga (PEFI)", SP, Brazil). A survey of zoosporic fungi from artificial lakes of the Fontes do Ipiranga State Park, in the city of São Paulo, São Paulo State, Brazil, yielded the isolation of 41 taxa with 36 species. Twenty-three taxa belong to Chytridiales, Monoblepharidales and Spizellomycetales of the Phylum Chytridiomycota, Fungi Kingdom and 18 belong to Saprolegniales and Peronosporales, Phylum Oomycota, Straminipila Kingdom. Of these, 14 are first-time records for this State Park: Aphanomyces helicoides von Minden, Catenochytridium kevorkianii Sparrow, Catenochytridium sp., Chytriomyces appendiculatus Karling, C. aureus Karling, C. hyalinus Karling, C. spinosus Fay, Diplophlyctis asteroidea Dogma, D. complicata (Willoughby) Dogma, Karlingia dubia Karling, Nowakowskiella hemisphaerospora Shanor, Saprolegnia australis Elliott, Septochytrium variabile Berdan and Truittella sp., which are described, commented and illustrated. The last genus is reported for the first time for Brazil.
\end{abstract}

Key words: diversity, Chytridiomycota, Oomycota, Atlantic rainforest, Brazil

\section{Introdução}

O Parque Estadual das Fontes do Ipiranga (PEFI) constitui importante área verde localizada na cidade de São Paulo, sendo um dos últimos remanescentes de Mata Atlântica em área urbana (Barbosa et al. 2002). Inseridas na área do PEFI estão diversas entidades públicas, dentre elas o Instituto de Botânica e o Jardim Botânico de São Paulo. Em função das missões próprias dessas entidades, da extensa e preservada porção de vegetação e por constituir rota migratória de aves aquáticas, o Parque configura-se como área de grande importância ambiental e social. Assim, destaca-se seu papel como repositório de biodiversidade, laboratório natural para pesquisas básicas e aplicadas, programas de Educação Ambiental, fator moderador do microclima local, fator mantenedor do lençol freático e como importante área de lazer (Barbosa 1993). Entretanto, verifica-se intensa degradação ambiental causada por atividades humanas, como a deposição de lixo de diversos tipos e o despejo de esgoto doméstico nos corpos d'água do Parque (Reis 2002).

Diversos estudos têm sido conduzidos no PEFI visando o conhecimento e a preservação da biodiversidade local. Trabalhos com fungos são ainda necessários, sendo que a maioria dos existentes possui enfoque taxonômico, raros os com enfoque ecológico. Os estudos com fungos zoospóricos contribuem de forma significativa para o conhecimento de sua

\footnotetext{
Instituto de Botânica, C. Postal 3005, 01061-970 São Paulo, SP, Brasil

2 Autor para correspondência: zottarelli@uol.com.br
} 
diversidade (Beneke \& Rogers 1962; Furtado 1965; Milanez 1965a; b; 1984; Milanez \& Val 1969; Rogers et al. 1970; Lyra \& Milanez 1974; Pelizon \& Milanez 1979; Milanez \& Trufem 1981; 1984). Monografias mais recentes foram elaboradas englobando as ordens Blastocladiales, Chytridiales, Lagenidiales, Leptomitales, Monoblepharidales, Peronosporales e Saprolegniales (Milanez et al. 1994; 1995; 1996; 2003; Pires-Zottarelli et al. 1995; 1996a; b).

Os fungos zoospóricos são caracterizados por apresentarem flagelos em suas estruturas de reprodução assexuada (zoósporos) e/ou sexuada (gametas). Possuem distribuição cosmopolita e ocorrem geralmente como sapróbios em substratos celulósicos, quitinosos e queratinosos, contribuindo para a manutenção do fluxo de energia e produtividade nos ecossistemas terrestres e aquáticos. Podem também ser parasitas de algas, anfíbios, peixes, crustáceos, briófitas, pteridófitas, plantas fanerogâmicas, de outros fungos e do homem (Alexopoulos et al. 1996).

Atualmente, os fungos zoospóricos estão enquadrados em três reinos: Protista, Stramenopila e Fungi, sendo a designação "fungos" utilizada de maneira didática para este grupo de organismos (Alexopoulos et al. 1996). Conforme proposto por Dick (2001), a designação de Reino Straminipila é a terminologia mais adequada e está sendo utilizada pelos especialistas. Devido às constantes alterações na taxonomia do grupo optou-se pela classificação contida em Hawksworth et al. (1995) para classes, ordens e famílias.

O objetivo deste trabalho foi o de incrementar o conhecimento sobre a diversidade de fungos zoospóricos do PEFI, sendo aqui descritos, comentados e ilustrados os 14 táxons isolados pela primeira vez na área.

\section{Material e métodos}

O PEFI situa-se na região sudeste do município de São Paulo, entre os paralelos $23^{\circ} 38^{\prime} 08^{\prime \prime S}$ e $23^{\circ} 40^{\prime} 18^{\prime \prime} \mathrm{S}$ e os meridianos $46^{\circ} 36^{\prime} 48^{\prime \prime} \mathrm{W}$ e $46^{\circ} 38^{\prime} 00^{\prime \prime} \mathrm{W}$, com área total de 526,38 ha. O clima da área, segundo o sistema internacional de Köppen, pertence aos tipos Cwa e Cwb, isto é, mesotérmico, de inverno seco, com precipitação anual acima de $1.000 \mathrm{~mm}$ (Fernandes et al. 2002). As várias nascentes existentes no Parque são formadas pelo afloramento do lençol freático e dão origem as cabeceiras do riacho do Ipiranga. A Reserva inclui 10 sub-bacias hidrográficas, as quais podem ser agrupadas, em escala maior, em três sub-bacias que fazem parte da grande bacia do rio Tietê. Destas, uma se encontra quase que inteiramente canalizada. As outras duas são referidas como sub-bacia das Garças e sub-bacia das Ninféias, onde se localizam o Lago das Garças e o das Ninféias (Bicudo et al. 2002; Fernandes et al. 2002; Pereira et al. 2002).

O Lago das Garças recebe as águas de reservatórios situados à montante (Fundação Parque Zoológico e Instituto Astronômico e Geofísico da USP), estando localizado em área sob jurisdição do Instituto de Botânica. É considerado sistema poluído, pois vem sofrendo acelerado processo de eutrofização, facilmente evidenciado pelas constantes "florações" de cianobactérias e pelo mau cheiro, os quais são, eventualmente, seguidos por mortandade de peixes. Como principal fonte de impacto, está a interferência antrópica por meio do lançamento de esgoto doméstico, sem tratamento. Por se tratar de área verde metropolitana, deve-se considerar ainda a influência da poluição atmosférica e do processo de acidificação das águas. O lago é considerado pequeno, medindo pouco mais de $88.100 \mathrm{~m}^{2}$, com profundidade máxima de 4,7 m e sete entradas pontuais, duas das quais são responsáveis pelas maiores cargas de poluição orgânica, e uma saída. Conforme Índice de Estado Trófico (IET), o sistema é classificado como hipereutrófico e pelo IET de Carlson modificado, como eutrófico.

O Lago das Ninféias, também localizado em área sob jurisdição do Instituto de Botânica, é considerado um sistema mesotrófico, não estando sujeito às diferentes formas de impactação observadas no Lago das Garças. Foi construído pelo barramento de um córrego, com finalidade paisagística, localizando-se na área central de visitação pública do Jardim Botânico de São Paulo. É um lago menor que o Lago das Garças, medindo $5.500 \mathrm{~m}^{2}$, com profundidade máxima de $3,6 \mathrm{~m}$, possuindo duas entradas e uma saída (Bicudo et al. 2002).

Para o levantamento dos fungos zoospóricos, amostras de água do Lago das Garças e das Ninféias foram coletadas bimestralmente, de janeiro/2001 a janeiro/2002. Foram estabelecidos 15 pontos de amostragem no Lago das Garças e oito no Lago das Ninféias. As amostras, aproximadamente $100 \mathrm{~mL}$, foram tratadas segundo técnica mencionada por Milanez (1989), a qual consiste na iscagem das amostras, em laboratório, com substratos celulósicos, quitinosos e queratinosos (sementes de Sorghum spp. previamente fervidas, epiderme de cebola, ecdise de 
cobra, palha de milho, celofane, exo-esqueleto de camarão, pólen de Pinus spp. e fios de cabelo louro de crianças).

Para estudo e identificação do grupo foram utilizadas literaturas específicas: Sparrow (1960) e Karling (1977) para Chytridiomycota; Dick (1973) para Saprolegniales; Johnson (1956) para o gênero Achlya; Scott (1961) para Aphanomyces; Seymour (1970) para Saprolegnia; Plaats-Niterink (1981) para Pythium e Johnson et al. (2002) para Saprolegniaceae, além de outros trabalhos contendo descrições originais de táxons.

\section{Resultados e discussão}

Foram isolados 41 táxons de fungos zoospóricos, a partir de 458 isolamentos, sendo 36 identificados em nível específico. Os táxons listados abaixo, marcados com asterisco, constituem novas citações para o PEFI e são descritos, comentados e ilustrados neste trabalho. Do total de táxons isolados, 23 pertencem ao Reino Fungi, Filo Chytridiomycota, ordem Chytridiales (Catenochytridium hemicysti Knox, ${ }^{*}$ C. kevorkianii Sparrow, *Catenochytridium sp., Catenophlyctis variabilis Karling, *Chytriomyces appendiculatus Karling, ${ }^{*} C$. aureus Karling, ${ }^{*} C$. hyalinus Karling, ${ }^{*}$ C. spinosus Fay, Cladochytrium replicatum Karling, *Diplophlyctis asteroidea Dogma, *D. complicata (Willoughby) Dogma, D. sarcoptoides Dogma, Nowakowskiella elegans Schroeter, ${ }^{*} N$. hemisphaerospora Shanor, Polychytrium aggregatum Ajello, Rhizophlyctis petersenii Karling, Rhizophydium elyensis Sparrow, $R$. sphaerotheca Zopf, *Septochytrium variabile Berdan e *Truittella sp.); Monoblepharidales (Gonapodya prolifera (Cornu) Fischer) e Spizellomicetales (* Karlingia dubia Karling e K. rosea (De Bary \& Woronin) Johanson). Os demais pertencem ao Reino Straminipila, Filo Oomycota, ordem Saprolegniales (Achlya apiculata de Bary, A. dubia Coker, A. flagellata Coker, A. prolifera Nees, A. proliferoides Coker, A. radiosa Maurizio, *Aphanomyces helicoides von Minden, A. stellatus de Bary, Dictyuchus pseudodictyon Coker \& Braxton, *Saprolegnia australis Elliott, S. diclina Humphrey, S. ferax (Gruith.) Thuret, S. furcata Maurizio, S. parasitica Coker e Thraustotheca clavata (de Bary) Humphrey) e Peronosporales (Pythium sp. "Grupo G", Pythium sp. - "Grupo P" e Pythium sp. "Grupo T"). O gênero Truitella é reportado pela primeira vez para o Brasil.
As descrições e ilustrações dos táxons anteriormente isolados no PEFI poderão ser consultadas em Milanez et al. (1994; 1995; 1996; 2003) e Pires-Zottarelli et al. (1995; 1996a; b). As novas citações são descritas abaixo dentro de suas respectivas ordens e famílias.

\section{CHYTRIDIALES}

\section{CHYTRIDIACEAE}

Chytriomyces appendiculatus Karling, Bull. Torrey Bot. Club. 74: 335. 1947.

Fig. 1

Talo eucárpico, monocêntrico, extra e/ou intramatrical. Zoosporângios apendiculados, operculados, hialinos quando jovens, tornando-se amarelados e com paredes espessadas quando mais velhos, variáveis em forma e tamanho, irregularmente piriformes e/ou reniformes, $62-100 \times 45-87 \mu \mathrm{m}$, alguns esféricos, 52-112 $\mu \mathrm{m}$ diâm. Zoósporos encistados, 5-6 $\mu \mathrm{m}$ diâm., com uma gotícula lipídica conspícua. Esporos de resistência ausentes.

Material examinado: BRASIL. São Paulo: São Paulo, Parque Estadual das Fontes do Ipiranga, Lago das Garças e das Ninféias, amostras de água, 23/I/2001, 22/III/2001, 21/V/2001, 23/VII/2001, 24/IX/2001, 20/XI/2001, 15/I/2002, M. Rocha.

A presença de zoosporângios apendiculados de tamanho e formas variadas, em substrato quitinoso, são características da espécie (Karling 1947). O exoesqueleto utilizado como isca quitinosa apresentou coloração amarelada devido à abundância de zoosporângios do espécime, sendo o substrato facilmente decomposto. A espécie foi isolada pela primeira vez no Brasil de amostras de água e solo de áreas de cerrado do Estado de São Paulo (C.L.A. Pires-Zottarelli, dados não publicados). Os espécimes isolados apresentaram zoosporângios maiores que os relatados na descrição original de Karling (1947), que os cita de 10-80 $\mu \mathrm{m}$ diâm., as demais características concordam com as descritas pelo autor.

Chytriomyces aureus Karling, Am. J. Bot. 32: 363.1945.

Fig. 2

Talo eucárpico, monocêntrico, extra e/ou intramatrical. Zoosporângios amarelados, operculados, esféricos, 32-68 $\mu \mathrm{m}$ diâm.; parede lisa. Apófise subesporangial. Liberação dos zoósporos por meio de opérculo localizado apical ou subapicalmente nos 
zoosporângios. Zoósporos encistados, 3-4 $\mu \mathrm{m}$ diâm., com uma gotícula lipídica amarelo-ouro. Esporos de resistência ausentes.

Material examinado: BRASIL. São Paulo: São Paulo, Parque Estadual das Fontes do Ipiranga, Lago das Garças e das Ninféias, amostras de água, 23/I/2001, 22/III/2001, 21/V/2001, 23/VII/2001, 24/IX/2001, 20/XI/2001, 15/I/2002, M. Rocha.

A presença de zoosporângios esféricos operculados, de coloração amarelo-ouro, dada pela coloração da gotícula lipídica dos zoósporos é característica marcante da espécie. É encontrada crescendo saprobicamente em substratos quitinosos, porém não é estritamente quitinófila, pois também foi isolada de substratos celulósicos (Sparrow 1960). A descrição original é de Karling (1945), o qual coletou espécimes em exúvia de inseto e de substrato quitinoso na cidade de Flores Nabuco, perto de Manaus (AM). Freqüente em isca quitinosa e queratinosa em amostras de água e solo de áreas de cerrado do Estado de São Paulo (C.L.A. Pires-Zottarelli, dados não publicados) e do Piauí (J.R.S. Rocha, dados não publicados). Os espécimes apresentaram zoosporângios maiores que os descritos por Karling (1945), que os cita com 8-49 $\mu \mathrm{m}$ diâm.

Chytriomyces hyalinus Karling, Am. J. Bot. 32: 363.1945.

Fig. 3-4

Talo eucárpico, monocêntrico, extra e/ou intramatrical. Zoosporângios operculados, hialinos, esféricos, 30-67 ㅆm diâm.; parede lisa. Liberação dos zoósporos por meio de opérculo localizado apical ou subapicalmente nos zoosporângios. Zoósporos encistados, 4-5 $\mu \mathrm{m}$ diâm., com uma gotícula lipídica hialina. Esporos de resistência esféricos, 14-18 $\mu \mathrm{m}$ diâm.; parede lisa, espessa, âmbar-claro, apresentando gotas lipídicas.

Material examinado: BRASIL. São Paulo: São Paulo, Parque Estadual das Fontes do Ipiranga, Lago das Garças e das Ninféias, amostras de água, 23/I/2001, 22/III/2001, 21/V/2001, 23/VII/2001, 24/IX/2001, 20/XI/2001, 15/I/2002, M. Rocha.

Normalmente ocorre associado à Chytriomyces aureus em substrato quitinoso, sendo distinguidos pela coloração dos zoosporângios. Foi descrito de exúvia de inseto e substrato quitinoso coletados na cidade de Flores Nabuco, perto de Manaus (AM), por Karling (1945). Sua ocorrência também foi relatada no Estado de São Paulo por Booth (1979) e Rocha \& PiresZottarelli (2002), no Piauí, por J.R.S. Rocha (dados não publicados) e em coletas em igarapés em Manaus (AM), por M.I.L. Silva (dados não publicados). Freqüente em iscas quitinosa e queratinosa em amostras de água e solo de cerrado do Estado de São Paulo (C.L.A. Pires-Zottarelli, dados não publicados). Os espécimes isolados apresentaram características que concordam com a descrição de Karling (1945) e Rocha \& Pires-Zottarelli (2002).

Chytriomyces spinosus Fay, Mycologia 39: 152. 1947.

Fig. 5

Talo eucárpico, monocêntrico, extra e/ou intramatrical. Zoosporângios operculados, hialinos, obpiriformes, $22-35 \times 30-47 \mu \mathrm{m}$; parede ornamentada com espinhos simples ou bifurcados. Liberação dos zoósporos por meio de opérculo delicado localizado apicalmente nos zoosporângios. Zoósporos encistados, 4-5 $\mu \mathrm{m}$ diâm., com uma gotícula lipídica conspícua. Esporos de resistência ausentes.

Material examinado: BRASIL. São Paulo: São Paulo, Parque Estadual das Fontes do Ipiranga, Lago das Garças e das Ninféias, amostras de água, 23/I/2001, 21/V/2001, 23/VII/2001, 24/IX/2001, 20/XI/2001, 15/I/2002, M. Rocha.

A presença de zoosporângios hialinos operculados com ornamentações espinhosas é característica da espécie, que é sapróbia e comum em substrato celulósico, tendo sido descrita por Fay (1947) de amostras de solo coletadas em New Jersey (EUA). Isolada pela primeira vez no Brasil por M.I.L. Silva (dados não publicados) em amostras de água e solo de igarapés de Manaus (AM). Possui ocorrência relatada para o Estado do Piauí (J.R.S. Rocha, dados não publicados) e para áreas de cerrado do Estado de São Paulo (C.L.A. Pires-Zottarelli, dados não publicados). As características apresentadas pelos espécimes concordam com a descrição original de Fay (1947).

\section{CLADOCHYTRIACEAE}

Nowakowskiella hemisphaerospora Shanor, Am. J. Bot., 29: 174. 1942.

Fig. 6-8

Talo eucárpico, policêntrico, extra-intramatrical. Rizomicélio extenso, ramificado. Zoosporângios operculados, hialinos, apofisados ou não, esféricos, 30-37 $\mu \mathrm{m}$ diâm., piriformes, 40-50×35-40 $\mu \mathrm{m}$; parede lisa. Liberação dos zoósporos por meio de 1 a 2 papilas; zoósporos encistados 5-6 $\mu \mathrm{m}$ diâm., com uma gotícula lipídica conspícua. Esporos de resistência hialinos, hemisféricos, 15-20×12-18 $\mu \mathrm{m}$; parede lisa. 


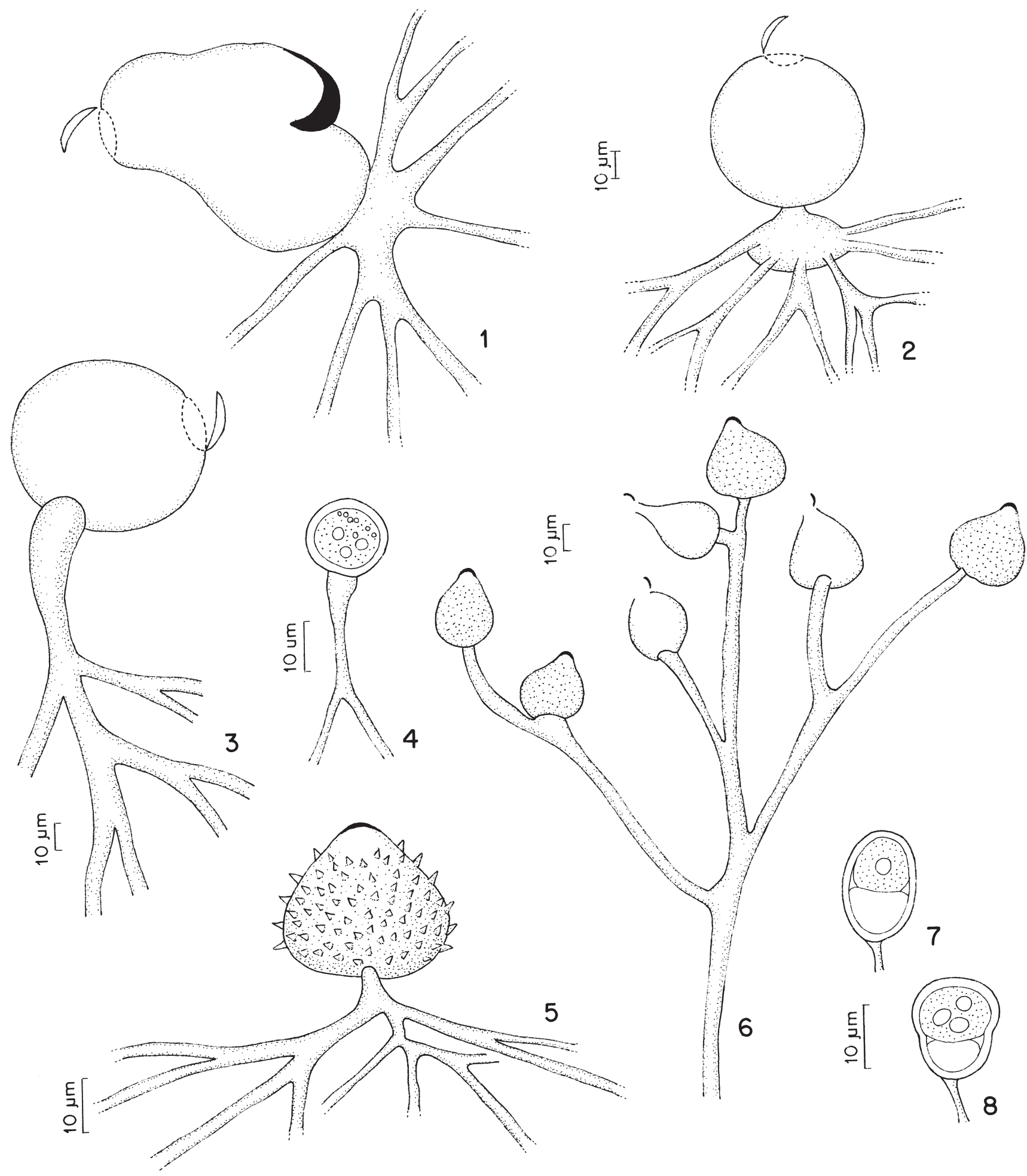

Figuras 1-8. 1. Chytriomyces appendiculatus Karling. Zoosporângio operculado. 2. Chytriomyces aureus Karling. Zoosporângio operculado com apófise. 3-4. Chytriomyces hyalinus Karling. 3. Zoosporângio operculado. 4. Esporo de resistência. 5. Chytriomyces spinosus Fay. Zoosporângio operculado com ornamentações espinhosas. 6-8. Nowakowskiella hemisphaerospora Shanor. 6. Talo policêntrico com zoosporângios operculados. 7-8. Esporos de resistência hemisféricos. 
Material examinado: BRASIL. São Paulo: São Paulo, Parque Estadual das Fontes do Ipiranga, Lago das Garças, amostra de água, 22/III/2001, M. Rocha.

Talo policêntrico, rizomicélio extensivo, zoosporângios operculados e a presença de esporos de resistência hemisféricos são características da espécie. Descrita por Shanor (1942) como sapróbia em iscas de celofane de amostras de água em Illinois (EUA). A espécie foi relatada pela primeira vez para o Brasil de amostras de água do município de Cubatão (SP) (Schoenlein-Crusius et al. 2006). Os isolados diferiram da descrição de Sparrow (1960), pois apresentaram zoosporângios maiores que os citados pelo autor, que cita de 7,5-14,2×9,5-28 $\mu \mathrm{m}$.

Septochytrium variabile Berdan, Am. J. Bot. 26: 461. 1939.

Fig. 9-12

Talo eucárpico, policêntrico, extra-intramatrical. Rizomicélio ramificado, septado. Zoosporângios operculados, esféricos, 37-95 um diâm., ovais, 50-95× 30-52 $\mu \mathrm{m}$, alguns irregulares; parede lisa. Liberação dos zoósporos por meio de opérculo. Zoósporos encistados, 4-5 $\mu \mathrm{m}$ diâm., com uma gotícula lipídica. Esporos de resistência âmbar, apresentando gotas lipídicas, esféricos, 37-50 $\mu \mathrm{m}$ diâm. e/ou ovais, 37-65× 30-42 $\mu \mathrm{m}$; parede lisa.

Material examinado: BRASIL. São Paulo: São Paulo, Parque Estadual das Fontes do Ipiranga, Lago das Garças, amostras de água, 23/I/2001, 22/III/2001, 21/V/2001, 23/VII/2001, 24/IX/2001, 15/I/2002, M. Rocha.

A presença de septos ou constrições no rizomicélio, zoosporângios operculados e uma única gotícula lipídica nos zoósporos são características marcantes da espécie (Berdan 1939). É comum em substratos celulósicos como celofane, epiderme de cebola e palha de milho, em água e em solo. Ocorre no Brasil nos Estados de São Paulo (Booth 1979; Pires-Zottarelli \& Milanez 1993; Rocha \& Pires-Zottarelli 2002; SchoenleinCrusius et al. 2006) e no Piauí (J.R.S. Rocha, dados não publicados). As características dos espécimes isolados concordam com aquelas descritas originalmente por Berdan (1939). Diferiram da descrição de Pires-Zottarelli \& Milanez (1993) quanto ao tamanho dos esporos de resistência, que são citados como esféricos com 17-27 $\mu \mathrm{m}$. Os zoosporângios também foram maiores que os descritos por Rocha \& Pires-Zottarelli (2002), que citam esféricos de 22-30 $\mu \mathrm{m}$ e ovais de 20-50×12-37 $\mu \mathrm{m}$.

\section{ENDOCHYTRIACEAE}

Catenochytridium kevorkianii Sparrow, Rev. Soc. Cubana Bot. 9: 70. 1952.

Fig. 13

Talo eucárpico, monocêntrico, extra e/ou intramatrical. Zoosporângios operculados, ovais e/ou reniformes, $62-100 \times 50-75 \mu \mathrm{m}$, alguns irregulares; parede lisa. Apófises presentes, simples ou compostas, esféricas ou subesféricas; rizóides catenulados. Liberação dos zoósporos por meio de opérculo apical. Zoósporos encistados, 6-7 $\mu \mathrm{m}$ diâm., com uma gotícula lipídica conspícua; cisto do zoósporo persistente localizado na base. Esporos de resistência ausentes.

Material examinado: BRASIL. São Paulo: São Paulo, Parque Estadual das Fontes do Ipiranga, Lago das Garças, amostra de água, 22/III/2001, M. Rocha.

As características típicas da espécie são a presença de rizóides catenulados, zoosporângios operculados e cisto do zoósporo com localização basal (Sparrow 1952). Protuberâncias no zoosporângio, normalmente citadas em literatura (Sparrow 1960; Karling 1977; Pires-Zottarelli \& Milanez 1993; Rocha \& Pires-Zottarelli 2002), não foram observadas nos espécimes estudados. É uma espécie sapróbia em substratos celulósicos como epiderme de cebola e palha de milho. Foi citada pela primeira vez para o Brasil por Pires-Zottarelli \& Milanez (1993), isolada de amostras de água e solo coletadas na Represa do Lobo ("Broa") no Estado de São Paulo. Ocorre também nos Estados do Amazonas (M.I.L. Silva, dados não publicados) e no Piauí (J.R.S. Rocha, dados não publicados). As características apresentadas pelos isolados diferem da descrição original de Sparrow (1952), pois possuem zoosporângios maiores, este autor os cita com 40-43× 35-36 $\mu \mathrm{m}$. Os espécimes apresentaram também zoosporângios maiores que os isolados por PiresZottarelli \& Milanez (1993), 24-66×20-56 $\mu \mathrm{m}$ e, por Rocha \& Pires-Zottarelli (2002), 45-72×37-50 $\mu \mathrm{m}$.

\section{Catenochytridium sp.}

Fig. 14

Talo eucárpico, monocêntrico, extra e/ou intramatrical. Zoosporângios operculados, lobulados, 47$70 \mu \mathrm{m}$ diâm.; parede lisa. Apófises simples ou compostas, esféricas ou subesféricas; rizóides catenulados. Liberação dos zoósporos por meio de opérculo; cisto do zoósporo localizado no ápice. Zoósporos encistados, 6-10 $\mu \mathrm{m}$ diâm. Esporos de resistência ausentes. 
Material examinado: BRASIL. São Paulo: São Paulo, Parque Estadual das Fontes do Ipiranga, Lago das Ninféias, amostra de água, 21/V/2001, M. Rocha.

Embora o espécime apresentasse características do gênero Catenochytridium, zoosporângios lobulados não são relatados para as espécies conhecidas. Foi isolado de substratos celulósicos como epiderme de cebola e palha de milho. Isolados com as mesmas características foram encontrados em amostras de água e solo de cerrado do Estado de São Paulo (C.L.A. Pires-Zottarelli, dados não publicados). Estudos mais aprofundados não puderam ser realizados, pois o espécime não se desenvolveu nos novos substratos utilizados como "iscas", entretanto, faz-se necessário o seu registro para subsidiar futuros estudos na área do Parque.

Diplophlyctis asteroidea Dogma, Trans. Br. mycol. Soc. 67: 255. 1976.

Fig. 15-16

Talo eucárpico, monocêntrico, extra-intramatrical. Zoosporângios inoperculados, apofisados, piriformes 37-50×25-45 $\mu \mathrm{m}$. Zoósporos encistados, 4-5 $\mu \mathrm{m}$ diâm., com uma gotícula lipídica, liberados por meio de um tubo de descarga; cisto do zoósporo persistente. Esporos de resistência abundantes, ornamentados, esféricos, 20-25 $\mu \mathrm{m}$ diâm. ou irregulares; ornamentações tuberculadas, muitas vezes pontiagudas, apresentando gotas lipídicas.

Material examinado: BRASIL. São Paulo: São Paulo, Parque Estadual das Fontes do Ipiranga, Lago das Garças, amostra de água, 22/III/2001, M. Rocha.

Zoosporângios inoperculados, apófises subesporangiais e esporos de resistência com ornamentações tuberculadas, dando aos mesmos um formato estrelado, são características da espécie. Sapróbia em substrato quitinoso, tendo sido descrita por Dogma (1976) a partir de exo-esqueleto de camarão utilizado como isca, em amostras provenientes de Michigan (EUA). Foi citada pela primeira vez para o Brasil por M.I.L. Silva (dados não publicados) de amostras de igarapés de Manaus (AM). Os isolados apresentaram esporos de resistência pouco maiores que os descritos por Dogma (1976), que cita de 12-20 $\mu \mathrm{m}$ diâm.

Diplophlyctis complicata (Willoughby) Dogma, Nova Hedwigia 25: 144. 1974.

Fig. 17-18

Basiônimo: Nephrochytrium complicatum Willoughby, Nova Hedwigia, 3: 439. 1962.
Talo eucárpico, monocêntrico, extra-intramatrical. Zoosporângios inoperculados, esféricos, 22-35 $\mu \mathrm{m}$ diâm., ocasionalmente piriformes, $25-45 \times 20-30 \mu \mathrm{m}$ ou irregulares; apofisados; parede lisa. Zoósporos encistados 4-5 m diâm., com uma gotícula lipídica, liberados por meio de 1-2 tubos de descarga; cisto do zoósporo persistente. Esporos de resistência de coloração âmbar, ornamentados, esféricos, 22-35 $\mu \mathrm{m}$ diâm.; ornamentações franjadas.

Material examinado: BRASIL. São Paulo: São Paulo, Parque Estadual das Fontes do Ipiranga, Lago das Garças, amostras de água, 21/V/2001, 24/IX/2001, 15/I/2002, M. Rocha.

Presença de zoosporângios inoperculados apofisados, cisto do zoósporo persistente e esporos de resistência com ornamentações franjadas caracterizam a espécie. Foi descrita por Willoughby (1962) como Nephrochytrium complicatum; entretanto, a ausência de opérculo levou I.J. Dogma a incluir a espécie no gênero Diplophlyctis (Dogma 1974). Ocorre como sapróbia em substratos quitinosos, no entanto, Rocha \& Pires-Zottarelli (2002) isolaram esta espécie de substratos celulósicos utilizados como iscas na Represa do Guarapiranga, São Paulo, SP. Foi mencionada pela primeira vez no Brasil de amostras de água do município de Cubatão, SP (Schoenlein-Crusius et al. 2006). As características dos espécimes isolados concordaram com as descritas por Dogma (1974) e Rocha \& Pires-Zottarelli (2002). Diferem de Rocha \& Pires-Zottarelli (2002), pois apresentaram zoosporângios menores que os citados pelos autores, de $37-62 \mu \mathrm{m}$.

\section{Truittella sp.}

Fig. 19

Talo eucárpico, monocêntrico, extra e/ou intramatrical. Zoosporângios operculados, esféricos, 42-82 $\mu \mathrm{m}$ diâm.; ovais $62-110 \times 37-62 \mu \mathrm{m}$ ou irregulares; parede lisa. Cisto do zoósporo persistente. Sistema rizoidal característico, tipicamente constrito em intervalos regulares, geralmente ramificado dicotomicamente. Esporos de resistência ausentes.

Material examinado: BRASIL. São Paulo: São Paulo, Parque Estadual das Fontes do Ipiranga, Lago das Garças, amostra de água, 22/III/2001, M. Rocha.

A única espécie descrita no gênero é Truittella setifera Karling caracterizada por apresentar setas partindo do cisto do zoósporo (Karling 1977), as quais não foram verificadas no presente espécime. É o primeiro relato do gênero para o Brasil. 


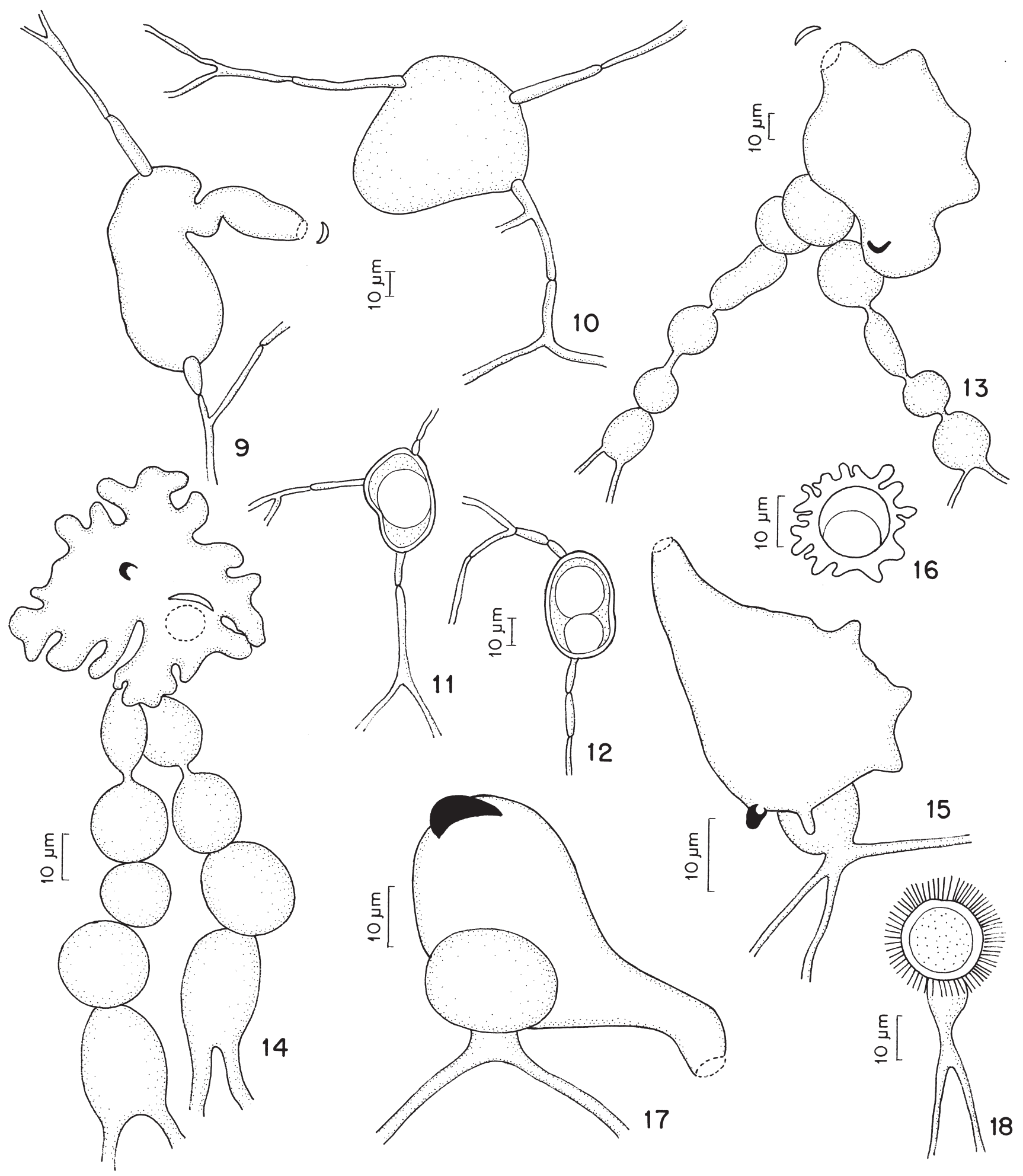

Figuras 9-18. Septochytrium variabile Berdan. 9-10. Zoosporângios operculados, rizomicélio constrito. 11-12. Esporos de resistência. 13. Catenochytridium kevorkianii Sparrow. Zoosporângio operculado com cisto basal. 14. Catenochytridium sp. Zoosporângio lobulado e operculado, cisto apical. 15-16. Diplophlyctis asteroidea Dogma. 15. Zoosporângio inoperculado com apófise e cisto. 16. Esporo de resistência ornamentado. 17-18. Diplophlyctis complicata (Willoughby) Dogma. 17. Zoosporângio inoperculado com apófise e cisto. 18. Esporo de resistência ornamentado. 


\section{SPIZELLOMYCETALES}

\section{SPIZELLOMYCETACEAE}

Karlingia dubia Karling, Mycologia 41: 513. 1949. Fig. 20-21

Talo eucárpico, monocêntrico, extra-intramatrical. Zoosporângios exoperculados, hialinos, esféricos, 42-90 $\mu$ m diâm., piriformes, 37-80×55-120 $\mu \mathrm{m}$; parede lisa. Sistema rizoidal ramificado, constrito, saindo de vários pontos da parede do zoosporângio. Zoósporos esféricos, 5-7 $\mu \mathrm{m}$ diâm.; com uma gotícula lipídica conspícua. Esporos de resistência âmbar, esféricos, 17-50 $\mu \mathrm{m}$ diâm. e ovais, $25-45 \times 40-62 \mu \mathrm{m}$; parede levemente enrugada.

Material examinado: BRASIL. São Paulo: São Paulo, Parque Estadual das Fontes do Ipiranga, Lago das Garças, amostras de água, 23/I/2001, 24/IX/2001, M. Rocha.

A presença de zoosporângios exoperculados, rizóides constritos e esporos de resistência levemente enrugados caracterizam a espécie, descrita de substrato quitinoso por Karling (1949) a partir de amostras de água e de solo de Maryland (EUA). Foi mencionada pela primeira vez para o Brasil de amostras de solo de Cubatão (SP), iscadas com substrato celulósico (Schoenlein-Crusius et al. 2006). Os espécimes observados diferiram da descrição original de Karling (1949), pois apresentaram esporos de resistência maiores. Este autor cita esporos de resistência esféricos de 8-20 $\mu \mathrm{m}$ diâm. e ovais 9-14×12-17 $\mu \mathrm{m}$, o mesmo acontecendo com relação à descrição de Konno (1984) que cita de 12-23 $\mu \mathrm{m}$.

\section{SAPROLEGNIALES}

\section{SAPROLEGNIACEAE}

Aphanomyces helicoides von Minden, Kryptogamenfl. Mark Brandenburg 5: 559. 1915.

Fig. 22-23

Micélio em ecdise de cobra e, limitado em semente de sorgo. Zoosporângios cilíndricos, longos. Zoósporos dispostos em uma única fileira dentro dos zoosporângios. Descarga dos zoósporos aclióide; zoósporos encistados, 8-10 $\mu \mathrm{m}$ diâm. Oogônios castanho-amarelados, esféricos, 32-42 $\mu \mathrm{m}$ diâm.; parede lisa. Anterídios díclinos e monóclinos, envolvendo o pedúnculo oogonial e oogônios; 1-5 por oogônio; células anteridiais clavadas, atracação lateral. Oósporos castanho-amarelados, 1 por oogônio, subcêntricos, esféricos, 25-30 $\mu \mathrm{m}$ diâm.
Material examinado: BRASIL. São Paulo: São Paulo, Parque Estadual das Fontes do Ipiranga, Lago das Garças e das Ninféias, amostras de água, 22/III/2001, 21/V/2001, 23/VII/2001, 24/IX/2001, 15/I/2002, M. Rocha.

A presença de ramos anteridiais envolvendo o pedúnculo oogonial, oogônios e, algumas vezes, as hifas adjacentes, oogônios castanho-amarelados, muitos agrupados, caracterizam esta espécie (Scott 1961). No entanto, os espécimes estudados não apresentaram oogônios agrupados. Johnson et al. (2002), em trabalho de revisão de Saprolegniaceae, colocaram a espécie como sinônimo de Aphanomyces laevis de Bary; entretanto, acreditamos que outros estudos devam ser realizados para aceitação da proposta.

As características dos espécimes isolados concordam com as descritas por Scott (1961) e Gomes et al. (2003). Espécie mencionada pela primeira vez para o Brasil por M.I.L. Silva (dados não publicados), estando sua ocorrência também relatada para os Estados de São Paulo (Gomes et al. 2003) e Piauí (J.R.S. Rocha, dados não publicados).

Saprolegnia australis Elliott, N.Z. J. Bot. 6: 103. 1968. Fig. 24-25

Micélio limitado em semente de sorgo. Zoosporângios filiformes, $65-320 \times 18-35 \mu \mathrm{m}$, renovação por proliferação interna. Descarga dos zoósporos saprolegnióide; zoósporos encistados 6-11 $\mu \mathrm{m}$ diâm. Oogônios laterais, intercalares, esféricos, 40-87 $\mu \mathrm{m}$ diâm. e piriformes, $57-105 \times 55-82 \mu \mathrm{m}$; parede lisa, com poros. Anterídios díclinos; células anteridiais tubulares, atracação lateral. Oósporos subcêntricos, esféricos, 25-32 $\mu \mathrm{m}$ diâm.

Material examinado: BRASIL. São Paulo: São Paulo, Parque Estadual das Fontes do Ipiranga, Lago das Garças, amostras de água, 21/V/2001; 23/VII/2001; 24/IX/2001, M. Rocha.

A predominância de anterídios díclinos, poros na parede do oogônio, oosferas geralmente não maturando e a presença de oósporos subcêntricos e abortivos são as características desta espécie (Elliott 1968). Foi isolada pela primeira vez no Brasil de amostras de água no município de Cubatão (SP) (Schoenlein-Crusius et al. 2006). As características dos espécimes isolados concordaram com a descrição original de Elliott (1968).

O presente trabalho complementa as monografias do grupo que relatam a ocorrência de 77 táxons de fungos zoospóricos para o Parque, perfazendo, com os resultados apresentados, 91 táxons, o que corresponde a um incremento de $18 \%$. Os novos relatos 


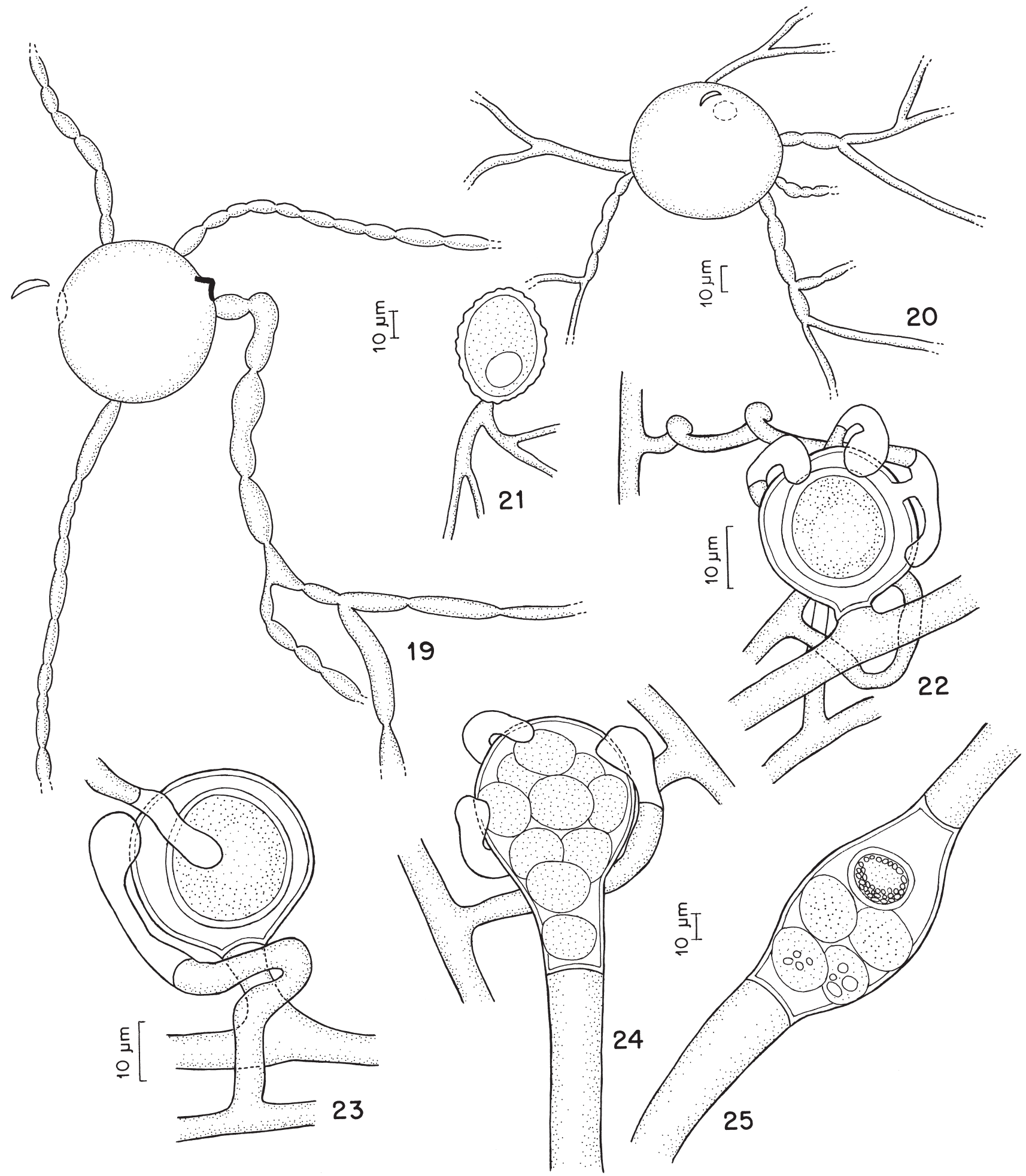

Figuras 19-25. 19. Truittella sp. Zoosporângio operculado com rizóides constritos. 20-21. Karlingia dubia Karling. 20. Zoosporângio operculado. 21. Esporo de resistência. 22-23. Aphanomyces helicoides von Minden. Oogônio lateral com oosporo e anterídios díclinos. 24-25. Saprolegnia australis Elliott. 24. Oogônio terminal com oosferas e anterídios díclinos. 25. Oogônio intercalar com oósporo subcêntrico e outros abortivos 
de fungos zoospóricos para o PEFI mostram que os ecossistemas são dinâmicos e passam por constantes modificações, o que leva à mudança da composição da micota, como pôde ser verificado neste levantamento.

\section{Agradecimentos}

As autoras agradecem à equipe do projeto "Tipologia, Monitoramento e Recuperação de Corpos d'água da Reserva Biológica do Parque Estadual das Fontes do Ipiranga, São Paulo, SP”, sob coordenação da Dra. Denise Bicudo, do Instituto de Botânica de São Paulo, pelo apoio irrestrito durante todo o período de estudo.

\section{Referências bibliográficas}

Alexopoulos, C.J.; Mims, C.W. \& Blackwell, M.B. 1996. Introductory Mycology. New York. John Wiley \& Sons.

Barbosa, L.M. 1993. Plano de ação para o Parque Estadual das Fontes do Ipiranga - PEFI. São Paulo, Relatório interno, Secretaria do Meio Ambiente.

Barbosa, L.M.; Potomati, A. \& Peccinini, A.A. 2002. O PEFI: Histórico e Legislação. Pp. 15-28. In: D.C. Bicudo; M.C. Forti, \& C.E.M. Bicudo (orgs.). Parque Estadual das Fontes do Ipiranga: unidade de conservação que resiste à urbanização de São Paulo. São Paulo, Secretaria do Meio Ambiente de São Paulo.

Beneke, E.S. \& Rogers, L. 1962. Aquatic Phycomycetes isolated in the States of Minas Gerais, São Paulo and Paraná, Brazil. Rickia 1: 181-193.

Berdan, H.B. 1939. Two new genera of operculate chytrids. American Journal of Botany 26(7): 459-463.

Bicudo, C.E.M.; Carmo, C.F.; Bicudo, D.C.; Henry, R.; Pião, A.C.S.; Santos, C.M. \& Lopes, M.R.M. 2002. Morfologia e morfometria de três reservatórios do PEFI. Pp. 143-160. In: D.C. Bicudo; M.C. Forti \& C.E.M. Bicudo (orgs.). Parque Estadual das Fontes do Ipiranga: unidade de conservação que resiste à urbanização de São Paulo. São Paulo, Secretaria do Meio Ambiente de São Paulo.

Booth, T. 1979. Strategies for study of fungi in marine and marine influenced ecosystems. Revista de Microbiologia 10: $123-138$.

Dick, M. 1973. Saprolegniales. Pp. 113-144. In: G.C. Ainsworth; F.K. Sparrow \& A.S. Sussman (eds.). The Fungi: an advanced treatise. New York, Academic Press.

Dick, M.W. 2001. Straminipilous Fungi: systematics of the Peronosporomycetes including accounts of the marine straminipilous protists, the plasmodiophorids and similar organisms. Dordrecht, Kluwer Academic Publishers.

Dogma Junior, I.J. 1974. Studies on chitinophylic Siphonaria, Diplophlyctis and Rizoclosmatium, Chytridiales. III. Nephochytrium complicatus Wiloughby: another Diplophlyctis with a sexual phase. Nova Hedwigia 25: 143-159.
Dogma Junior, I.J. 1976. Studies on chitinophilic Siphonaria, Diplophlyctis and Rhizoclosmatium, Chytridiales. V. Diplophlyctis asteroidea, a new species with assexual resting spores. Transactions of the British Mycological Society 67: 255-264.

Elliott, R.F. 1968. Saprolegnia terrestris Cookson and Saprolegnia australis sp. nov.: morphology variation in New Zealand Saprolegniaceae. New Zealand Journal of Botany 6(1): 94-105.

Fay, D.J. 1947. Chytriomyces spinosus nov. sp. Mycologia 39: $152-157$.

Fernandes, A.J.; Reis, L.A.M. \& Carvalho, A. 2002. Caracterização do meio físico. Pp. 49-62. In: D.C. Bicudo; M.C. Forti \& C.E.M. Bicudo (orgs.). Parque Estadual das Fontes do Ipiranga: unidade de conservação que resiste à urbanização de São Paulo. São Paulo, Secretaria do Meio Ambiente de São Paulo.

Furtado, J.S. 1965. A new aquatic fungi, Achlya benekei sp. nov. Rickia 2: 121-127.

Gomes, A.L.; Pires-Zottarelli, C.L.A.; Rocha, M. \& Milanez, A.I. 2003. Saprolegniaceae de áreas de cerrado do estado de São Paulo, Brasil. Hoehnea 30(2): 95-110.

Hawksworth, D.L.; Kirk, P.M.; Sutton, B.C. \& Pegler, D.M. 1995. Dictionary of the Fungi. Egham, International Mycological Institute.

Johnson Junior, T.W. 1956. The genus Achlya: morphology and taxonomy. Ann Arbor, University of Michigan Press.

Johnson Junior, T.W.; Seymour, R.L. \& Padgett, D.E. 2002. Biology and systematics of Saprolegniaceae. Disponível em $>$ www.uncw.edu/people/padgett/book. (Acesso em novembro/2002).

Karling, J.S. 1945. Brazilian chytrids. VI. Rhopalophlyctis and Chytriomyces, two new chitinophilic operculate genera. American Journal of Botany 32(7): 362-369.

Karling, J.S. 1947. New species of Chytriomyces. Bulletin of the Torrey Botanical Club 74: 334-344.

Karling, J.S. 1949. New monocentric eucarpic operculate chytrids from Maryland. Mycologia 41: 505-522.

Karling, J.S. 1977. Chytridiomycetarum Iconographia. Vaduz, J. Cramer.

Konno, K. 1984. Water moulds from Taiwan. Bulletin of the National Science Museum 10: 87-99.

Lyra, N.P. \& Milanez, A.I. 1974. Notas para o levantamento dos ficomicetos aquáticos do estado de São Paulo. Instituto de Micologia da Universidade Federal de Pernambuco 698: 1-27.

Milanez, A.I. 1965a. Myzocytium megastomum de Wild in São Paulo, Brazil. Rickia 2: 153-158.

Milanez, A.I. 1965b. Achlya brasiliensis, a new species from Brazil. Rickia 2: 183-189.

Milanez, A. I. 1984. Fungos zoospóricos do estado de São Paulo. II. Chytridiomycetes da Região Oeste. Rickia 11: 115-127.

Milanez, A.I. 1989. Fungos de águas continentais. Pp. 17-20. In: O. Fidalgo \& V.L.R. Bononi (coords.). Técnicas de coleta preservação e herborização de material botânico. Série Documentos. São Paulo, Instituto de Botânica de São Paulo. 
Milanez, A.I. \& Trufem, S.F.B. 1981. Ficomicetos em frutos submersos do Parque Estadual das Fontes do Ipiranga, São Paulo. Rickia 9: 7-15.

Milanez, A.I. \& Trufem, S.F.B. 1984. Fungos zoospóricos em frutos submersos do Parque Estadual das Fontes do Ipiranga, São Paulo. II. Rickia 11: 77-84.

Milanez, A.I. \& Val, F.C. 1969. Occurrence of Petersenia irregulare (H.E. Petersen) Sparrow in Brazil. Rickia 4: $75-82$.

Milanez, A.; Pires-Zottarelli, C.L.A. \& Schoenlein-Crusius, I.H. 1994. Criptógamos do Parque Estadual das Fontes do Ipiranga, São Paulo, SP. Fungos, 1: Monoblepharidales. Hoehnea 21(1/2): 157-161.

Milanez, A.; Pires-Zottarelli, C.L.A. \& Schoenlein-Crusius, I.H. 1995. Criptógamos do Parque Estadual das Fontes do Ipiranga, São Paulo, SP. Fungos, 2: Lagenidiales. Hoehnea 22(1/2): 115-123.

Milanez, A.I.; Pires-Zottarelli, C.L.A. \& Schoenlein-Crusius, I.H. 1996. Criptógamos do Parque Estadual das Fontes do Ipiranga, São Paulo, SP. Fungos, 5: Leptomitales. Hoehnea 23(1): 67-76.

Milanez, A.I.; Pires-Zottarelli, C.L.A., Schoenlein-Crusius, I.H. \& Lohmann, L.G. 2003. Criptógamos do Parque Estadual das Fontes do Ipiranga, São Paulo, SP. Fungos, 8: Blastocladiales. Hoehnea 30(1): 21-29.

Pelizon, M.H. \& Milanez, A.I. 1979. Ficomicetos parasitas de algas da região da grande São Paulo. Rickia 8: 51-61.

Pereira, S.Y.; Reis, L.A.M.; Oda, G.H. \& Iritani, M.A. 2002. Caracterização dos recursos hídricos subterrâneos. Pp. 63-74. In: D.C. Bicudo; M.C. Forti \& C.E.M. Bicudo (orgs.). Parque Estadual das Fontes do Ipiranga: unidade de conservação que resiste à urbanização de São Paulo. São Paulo, Secretaria do Meio Ambiente de São Paulo.

Pires-Zottarelli, C.L.A. \& Milanez, A.I. 1993. Fungos zoospóricos da Represa do Lobo ("Broa"). Novas citações para o Brasil. Revista Brasileira de Botânica 16: 205-220.

Pires-Zottarelli, C.L.A.; Milanez, A.I.; Schoenlein-Crusius, I.H. \& Lohmann, L.G. 1995. Criptógamos do Parque Estadual das Fontes do Ipiranga, São Paulo, SP. Fungos, 3: Peronosporales. Hoehnea 22(1/2): 125-133.
Pires-Zottarelli, C.LA.; Milanez, A.I.; Schoenlein-Crusius, I.H. \& Lohmann, L.G. 1996a. Criptógamos do Parque Estadual das Fontes do Ipiranga, São Paulo, SP. Fungos, 4: Saprolegniales. Hoehnea 23(1): 39-66.

Pires-Zottarelli, C.L.A.; Milanez, A.I.; Schoenlein-Crusius, I.H. \& Lohmann, L.G. 1996b. Criptógamos do Parque Estadual das Fontes do Ipiranga, São Paulo, SP. Fungos, 6: Chytridiales. Hoehnea 23(1): 77-90.

Plaats-Niterink, A.J. 1981. Monograph of genus Pythium. Studies in Mycology 21: 1-242.

Reis, L.A.M. 2002. Resíduos sólidos e líquidos encontrados no PEFI. Pp. 259-270. In: D.C. Bicudo; M.C. Forti \& C.E.M. Bicudo (orgs.). Parque Estadual das Fontes do Ipiranga: unidade de conservação que resiste à urbanização de São Paulo. São Paulo, Secretaria do Meio Ambiente de São Paulo.

Rocha, M. \& Pires-Zottarelli, C.L.A. 2002. Chytridiomycota e Oomycota da Represa do Guarapiranga, São Paulo, SP. Acta Botanica Brasilica 16(3): 287-309.

Rogers, A.L.; Milanez, A.I. \& Beneke, E.S. 1970. Additional aquatic fungi from São Paulo State. Rickia 5: 93-110.

Schoenlein-Crusius, I.H.; Milanez, A.I.; Trufem, S.F.B.; PiresZottarelli, C.L.A.; Grandi, R.A.P.; Santos, M.L. \& Giustra, K.C. 2006. Microscopic fungi in the Atlantic rainforest in Cubatão, São Paulo, Brazil. Brazilian Journal of Microbiology 37: 244-252.

Scott, W.W. 1961. A revision of the genus Aphanomyces. Technical Bulletin of the Virginia Agricultural Experiment Station 151: 1-95.

Seymour, R.L. 1970. The genus Saprolegnia. Nova Hedwigia 19(1/2): 1-124.

Shanor, L. 1942. A new fungus belonging to the Cladochytriaceae. American Journal of Botany 29: 174-179.

Sparrow Jr., F.K. 1952. A contribution to our knowledge of the Phycomycetes of Cuba. Revista de La Sociedad Cubana de Botanica 9: 68-74.

Sparrow Jr., F.K. 1960. Aquatic Phycomycetes. Ann Arbor, University of Michigan Press.

Willoughby, L.G. 1962. New species of Nephrochytrium from the English Lake District. Nova Hedwigia 3: 439-444. 